\title{
ACESSO À JUSTIÇA: PERSPECTIVAS HISTÓRICAS E O NOVO CÓDIGO DE PROCESSO CIVIL
}

\section{ACCESS TO JUSTICE: HISTORICAL PERSPECTIVES AND THE NEW CIVIL PROCEDURE CODE}

\author{
Aloísio Alencar Bolwerk ${ }^{1}$ \\ Lucimara Andreia Moreira Raddatz ${ }^{2}$ \\ João Paulo Macedo Magalhães ${ }^{3}$
}

\section{RESUMO}

O objetivo primeiro do presente texto será apresentar as diferentes concepções do conceito de acesso à justiça, cujo significado muda a depender do contexto em que seja interpretado. Ato contínuo, será demonstrado como as profundas alterações estruturais do processo o fizeram demandar empenho para conceber instrumentos capazes de atenuar a profunda crise na qual mergulhou o sistema judiciário. Ademais, será explicitado o papel do Novo Código de Processo Civil no melhoramento do aceso à justiça, bem como apontado quais dos seus dispositivos simbolizam a criação de um campo propício para o desenvolvimento de um processo verdadeiramente democrático.

Palavras-chave: Acesso à justiça; Cooperação; Contraditório substancial; Autocomposição.

\section{ABTRACT}

The first objective this text will present the different conceptions of the concept access to justice, whose meaning changes depending the context in which is interpreted.

\footnotetext{
${ }^{1}$ Doutor em Direito Privado pela Pontificia Universidade Católica de Minas Gerais. Professor Adjunto de Direito Constitucional da Universidade Federal do Tocantins - UFT e de Teoria do Direito do CEULP/ULBRA. Coordenador do Curso de Direito da Faculdade de Ciências Jurídicas de Paraíso do Tocantins. Advogado. Email: bolwerk@uft.edu.br

${ }^{2}$ Mestre em Prestação Jurisdicional e Direitos Humanos. Professora Assistente na Universidade Federal do Tocantins - UFT. Advogada E-mail: lucimara.raddatz@gmail.com

${ }^{3}$ Aluno do 70 Período do Curso de Direito da Universidade Federal do Tocantins - UFT. Membro do Grupo de $\begin{array}{lllllllll}\text { Pesquisa em } & \text { Processo Civil }\end{array}$ macedomagalhaes95@gmail.com
} 
Continuous act, will be demonstrated how the profound structural changes in the process have made it necessary to devise instruments capable of alleviating the deep crisis in which the judicial system has plunged. In addition, the role of New Code of Civil Procedure on improvement of access to justice as well as point out whitch of its devices symbolize the creation a field conducive to development a truly democratic process.

Keywords: Access to justice; Cooperation; Substantial contradiction; Autocomposition.

\section{CONSIDERAÇÕES INICIAIS}

De início, serão direcionados esforços para discriminar as construções históricas do conceito de "acesso à justiça". Assim, será feita uma abordagem dos dois grandes primeiros paradigmas da modernidade, quais sejam, o liberal e o social, onde foram endossadas as mudanças ocorridas na Jurisdição, nas feições do processo e na própria compreensão das funções do juiz. Posteriormente, será trabalhado o acesso à justiça segundo o paradigma procedimental do Estado Democrático de Direito, onde o conceito de acesso à justiça fora amoldado aos ditames democráticos.

Enquanto problemática, deixou-se evidenciado que a estruturação do sistema de justiça já não mais poderia atender às novas necessidades. A morosidade e ineficiência marcantes do judiciário, agora mais do que nunca, representavam um óbice à garantia do acesso à justiça, que a todos é devido, indistintamente.

É nessa ambiência que emerge a novel codificação processual civil, com auspiciosas mudanças, declaradamente vocacionadas a atenuar as críticas feitas em virtude de uma prestação judiciária ineficiente, com flagrante desrespeito à duração razoável do processo. Assim, os objetivos desta pesquisa procuraram delinear, de maneira não exaustiva, os dispositivos do Novo Código de Processo Civil aptos a viabilizar um aprimoramento do acesso à justiça, tais como a implementação, entre as normas processuais fundamentais, de garantias como a duração razoável do processo, consagrada no artigo 4ํㅜㄹ a inafastabilidade da jurisdição e o incentivo à solução consensual de litígios, alocadas no artigo $3^{\circ}$. 
Por derradeiro - e a partir de método dialético entre a codificação antiga e a novel legislação processual - serão pormenorizadas algumas inovações trazidas e que representam um campo para implementação efetiva de um processo verdadeiramente democrático e capaz de promover o ambicionado acesso à justiça, tais como a cooperação, o contraditório substancial e o dever de fundamentação das decisões judiciais.

\section{PERSPECTIVAS HISTÓRICAS DO CONCEITO DE ACESSO À JUSTIÇA}

\subsection{Acesso à Justiça no Estado Liberal}

Neste momento, serão direcionados esforços para discriminar as construções históricas do conceito de "acesso à justiça". Assim, será feita uma abordagem dos dois grandes primeiros paradigmas da modernidade, quais sejam, o liberal e o social, onde foram endossadas as mudanças ocorridas na Jurisdição, nas feições do processo e na própria compreensão das funções do juiz. Por derradeiro, será trabalhado o acesso à justiça segundo o paradigma procedimental do Estado Democrático de Direito.

O primeiro dos paradigmas, o liberal, surgiu influenciado pelos valores (o individualismo, o absenteísmo estatal, a defesa da liberdade e da propriedade privada) que emergiram com as revoluções burguesas do século XVII e XVIII. Nesta ambiência foi construída uma nova concepção de Estado que, após a derrocada do absolutismo, passou a ter seus poderes e funções limitados, com restrição de sua ingerência na vida social. Formou-se, assim, o que Bobbio denominou de "a grande dicotomia", onde o público e o privado passam a constituir regimes jurídicos diversos: ao estado incumbia a preservação da soberania e da ordem pública, enquanto as demais áreas da vida social estariam confiadas à iniciativa privada.

Nessa primeira acepção, o direito fora despido de valorações de ordem moral, política, sociológica e filosófica, ou seja, só eram consideradas jurídicas as exortações baseadas na interpretação do sentido literal da norma positivada. Essa "despolitização 
do discurso jurídico não permitia observar questões de inclusão social como um problema genuinamente da justiça, ou jurídico" (NUNES; TEIXEIRA, 2013, p. 21). No discurso jurídico liberal, sublinham os autores, a justiça era finalidade que somente deveria ser buscada pelos legisladores e não pelos juízes, cuja atividade estaria adstrita à mera subsunção (aplicação da norma ao caso concreto).

Nesse interim, o acesso à justiça era concebido simplesmente como exercício do direito de ação. Noutras palavras, significava tão somente o direito formal do indivíduo agravado de propor ou contestar uma ação (direito de ingresso em juízo). A atuação jurisdicional volta-se para questões relativas ao direito invocado pelo autor e isso, por si só, resumiria a distribuição da justiça. Aqui o juiz era mero espectador imparcial do debate assumido pelos sujeitos da lide, matinha sempre um comportamento passivo, isso porque os sujeitos parciais eram vislumbrados como soberanos na gestão de seus interesses. Aqui, diz-se que o acesso à justiça somente poderia ser alcançado por quem apresentasse condições financeiras de arcar com seus custos, caso contrário, estaria o jurisdicionado condenado ao acesso meramente formal, mas nunca efetivo da justiça. Fala-se de igualdade formal, não material (CAPPELLETTI apud NUNES; TEIXEIRA, 2013, p. 21).

Neste quadro, qualquer melhoramento do acesso à justiça restaria adstrito ao aprimoramento do direito de ação, sem se considerar a possibilidade de interpretação da norma pelo juiz, considerado apenas como "boca da lei".

\subsection{Acesso à Justiça no Estado Social}

O total desinteresse do Estado no regramento das relações da vida privada acabou por ensejar o acirramento das desigualdades sociais e econômicas, o que fez surgir a necessidade de buscar socorro no intervencionismo como forma de atenuar os transtornos criados pelo Estado Liberal. Assim, a atuação do Estado cresceu exponencialmente, o que fez surgir uma nova fase do constitucionalismo, a do Estado Social. 
Cumpre salientar que, não por acaso, foram intensificadas as investigações no campo do processo, agora visto como um potencial instrumento de transformação social.

\footnotetext{
Implementava-se no discurso processual a quebra completa do ideal de monopólio das partes e dos advogados no processo civil e do liberalismo processual, ao partir do pressuposto publicístico (...) do ativismo e protagonismo judicial (NUNES; TEIXEIRA, 2013, p. 29).
}

Assim, nessa fase, o objetivo do acesso à justiça seria dar efetividade aos direitos reconhecidos e recém constitucionalizados. Pode-se inferir que, agora, o acesso à justiça não estaria adstrito à mera propositura da demanda perante os órgãos do judiciário, como exercício do direito de ação, mas antes seria a plena efetivação dos interesses perseguidos, através de uma efetiva prestação jurisdicional (NUNES; TEIXEIRA, 2013, p. 29).

Após a derrocada do Estado Liberal e consequente ascensão do Estado Social, o acesso à justiça passou a ser vislumbrado como um meio através do qual as pessoas seriam providas da lei, bem como de cuidados com a saúde, habitação e educação, ou seja, o conceito de acesso à justiça estava ligado à capacidade do estado de efetivar os direitos sociais. Estava-se diante de uma expansão dos direitos sociais tendo como resultado uma explosão de litigiosidade.

Nota-se, ainda nesse período, um aumento nos poderes do juiz, que seria responsável por atuar de modo a "compensar os défices de desigualdade material", como dizem os processualistas, ou seja, o magistrado fora alçado ao patamar de protagonista do processo, enquanto as partes ficaram relegadas a segundo plano. Entretanto, esse reforço dos poderes do juiz ensejou um quadro de "atecnia" dos demais sujeitos do processo (percebe-se que não se pode trabalhar com o juiz solitariamente. Influenciado por tais circunstâncias, surge a proposta de construção de um processo colaborativo, conforme se explicitará adiante.

\subsection{Acesso à Justiça no paradigma procedimental do Direito}


Conforme explicitado alhures, a primeira concepção de acesso à justiça fora formatada no seio do Estado Liberal, cuidando-se tão somente do direito de ingresso em juízo, estando limitado pela igualdade formal, enquanto que a segunda concepção remonta à instauração do Estado interventor, vocacionado à efetivação de direitos sociais e da igualdade material. Não ignorando as construções anteriormente mencionadas, mas antes as absorvendo, Habermas constrói um novo paradigma, o "paradigma procedimental do direito". Nesse novo paradigma o cidadão deverá ter a oportunidade de influir na decisão (contraditório como direito de influência e não surpresa) (NUNES; TEIXEIRA, 2013, p. 61). Fala-se de um direito mais participativo, pluralista e aberto.

Nestes termos, a nova acepção de acesso à justiça pode ser concebida como a garantia de uma estrutura que permita o acesso à argumentação, à imparcialidade, à fundamentação, à certeza de que as decisões tomadas em favor ou prejuízo do jurisdicionado só se legitimarão se forem tomadas discursivamente. Nunes e Teixeira denominam o acesso à justiça estruturado segundo esses moldes de "acesso à justiça democrático" (2013, p. 67).

\subsection{Crise do Judiciário e os empecilhos ao acesso à Justiça}

Segundo destacado linhas atrás, a partir do marco do paradigma social pode-se notar uma tendência de ampliação dos processos de "juridificação" do direito positivo, o que quase resultou na presença do direito em todos os aspectos da vida social. Isso ensejou o aparecimento de um número excessivo de demandas, claramente incompatíveis com a rotina e recursos dos tribunais (NUNES; TEIXEIRA, 2013, p. 98).

Então, como é cediço, o sistema de justiça pátrio, não fugindo da regra que engloba diversos outros lugares do mundo, padece de uma crise que, pode-se sublinhar, advém de uma carência de recursos estruturais e humanos, de uma demora demasiada da efetivação da prestação jurisdicional e o do aumento exponencial de conflitos levados para apreciação do judiciário. 
A crise de que trata o presente esforço deixou evidenciado que a estruturação do sistema de justiça já não mais poderia atender às novas necessidades. A morosidade e ineficiência marcantes do judiciário, agora mais do que nunca, representavam um óbice à garantia do acesso à justiça, que a todos é devido, indistintamente.

Assim, expressamente vocacionado à solução dos litígios dentro de um prazo razoável, atenuando as críticas destinadas à um acesso à justiça demasiadamente ineficiente, a novel codificação processual civil emerge com promissoras mudanças. Procurar-se-á, portanto, discriminar aquelas que representam um aprimoramento e ampliação do acesso à justiça, bem como as que possuem potencial capacidade de assegurar um acesso à justiça efetivamente democrático.

\section{O NOVO CÓDIGO DE PROCESSO CIVIL E O APRIMORAMENTO DO ACESSO À JUSTIÇA}

Foram mais de quatro anos de tramitação legislativa e, após longa espera, foinos apresentado o Novo Código de Processo civil que, lista-se, é o primeiro de nossa história promulgado em regime democrático (CPC de 1939 - publicado durante o Estado Novo; CPC de 1973 - publicado durante a Ditadura Militar).

Conforme exortação do Ministro Celso de Mello, decano do Supremo Tribunal Federal, acredita-se que o Novo Código de Processo Civil vai "propiciar não só maior acessibilidade do cidadão ao sistema de jurisdição estatal ou aos modelos alternativos de composição dos litígios mediante conciliação, arbitragem ou mediação, mas conferir, também, real efetividade à cláusula constitucional que assegura a todos os cidadãos o direito à prestação jurisdicional sem dilações indevidas" (RODAS, 2017, on line). As disposições da novel codificação processual apresentam-se como auspiciosas, não apenas para a comunidade jurídica, mas antes para todas as instituições do país. 
Após um sem-número de contribuições doutrinárias, a própria estrutura do processo civil brasileiro foi reconstruída. Inúmeros foram os acréscimos feitos com a intenção de aprimorar o acesso à justiça, diminuindo o tempo de duração do processo e o número de sentenças proferidas pelos juízes (o estímulo à conciliação e à mediação, exemplificando). Ademais, assumiu o processo uma feição democrática, deixando de servir para o manejo de interesses privados (processo como instrumento das partes) e para os interesses públicos (processo como interesse social), passando a viabilizar o diálogo democráticos entre todos os sujeitos (partes, advogados, juízes) e a conciliação entre o público e o privado.

\subsection{Da razoável duração do processo}

O princípio da duração razoável do processo é, antes de tudo, assegurado na Convenção Americana de Direitos Humanos, Pacto de São José da Costa Rica, do qual o Brasil é signatário. Seu art. 8ํe estabelece que:

Art. 8. Toda pessoa terá o direito de ser ouvida, com as devidas garantias e dentro de um prazo razoável, por um juiz ou Tribunal competente, independente e imparcial, estabelecido anteriormente por lei, na apuração de qualquer acusação penal formulada contra ela, ou na determinação de seus direitos e obrigações de caráter civil, trabalhista, fiscal ou de qualquer outra natureza.

Trata-se do direito ao processo sem dilações indevidas, que possui como corolário o devido processo legal e o princípio da inafastabilidade da jurisdição (garantia constitucional do acesso à justiça) (DIDIER JR, 2016, p. 96). Ademais, a EC n. 45/2004, responsável pela reforma do poder judiciário, introduziu no art. 5o da Constituição Federal o inciso LXXIII, segundo o qual "a todos, no âmbito judicial e administrativo, são assegurados a duração razoável do processo e os meios que garantam a celeridade de sua tramitação.

Não bastasse as aludidas previsões e a regra de que os princípios do processo não dependem de intermediação legislativa para alcançarem efetivação, vez que 
gozam de eficácia plena, nos termos do art. 5ำ $\S 1, C F / 88$, o NCPC as ratificou no seu art. $4^{\circ}$, evidenciando que elas se aplicam inclusive na fase executiva: "as partes têm direito de obter em prazo razoável a solução integral do mérito, incluída a atividade satisfativa". O inciso II do art. 139 vem para reforçar o princípio: "art. 139. O juiz dirigirá o processo conforme as disposições deste Código, incumbindo-lhe: II - velar pela duração razoável do processo".

Na proa dos ensinamentos de Fredie Didier (2016), lembra TUCCI que a Corte Europeia de Direitos do Homem asseverou que, respeitadas as circunstâncias de cada caso, três são os critérios que devem ser observados para que se determine se a duração do processo é ou não razoável, a saber: 1) a complexidade do assunto; 2) o comportamento dos litigantes e de seus procuradores, ou da acusação e da defesa no processo; 3) a atuação do órgão jurisdicional (2003, p. 239). No Brasil, pode-se acrescentar como critério a análise da estrutura do órgão judiciário.

Cumpre salientar, então, que "processo devido é, pois, processo com duração razoável". Nega-se a ideia de existência de um princípio da celeridade. Processo não tem de ser rápido: deve demorar o tempo necessário e adequado à solução do caso submetido ao órgão jurisdicional (DIDIER JR, 2016, pp. 96-97).

O novo Código de Processo Civil foi enfático ao estabelecer que 0 jurisdicionado deve ter assegurado a solução efetiva e eficiente do seu litígio em tempo razoável.

\subsection{O Novo Código de Processo Civil e o incentivo à solução consensual dos conflitos}

A lei no 13.105/2015, que instituiu o novo Código de Processo Civil, estabeleceu no rol de suas normas fundamentais o artigo $3^{\circ}$, que consagra $\circ$ princípio da inafastabilidade da jurisdição, bem como o fomento aos meios consensuais de solucionar conflitos, seja por arbitragem, mediação ou conciliação.

Segundo o art. 3ํ do Código de Processo Civil: 
Não se excluirá da apreciação jurisdicional ameaça ou lesão a direito.

$\S 1$ ㅇ É permitida a arbitragem, na forma da lei.

$\S 2$ 을 Estado promoverá, sempre que possível, a solução consensual dos conflitos.

§ 3 A conciliação, a mediação e outros métodos de solução consensual de conflitos deverão ser estimulados por juízes, advogados, defensores públicos e membros do Ministério Público, inclusive no curso do processo judicial.

Cuidando da diferença conceitual entre mediação e conciliação, José Rogério Cruz e Tucci assevera que:

A mediação constitui um mecanismo de solução de conflitos na qual uma terceira pessoa, neutra e imparcial, fomenta o diálogo entre as partes, para que elas próprias construam, com autonomia e solidariedade, a melhor solução para o problema. Geralmente, é ela recomendada para litígios mais complexos, que envolvam várias questões entre as partes.

A conciliação, por sua vez, é um meio empregado em conflitos mais singelos e menos abrangentes, no qual o terceiro normalmente se porta de foram mais ativa, embora sempre neutra e imparcial. Normalmente, é um procedimento consensual mais breve, que trabalha alvitrando efetiva harmonia entre os litigantes (2003).

Outrossim, as referidas técnicas para fazer "desaparecer incompatibilidades", são regidas pelos princípios da oralidade, eficiência, economia, e flexibilização procedimental. Ademais cumpre ao juiz decidir, mediante análise das peculiaridades do caso concreto, qual técnica será mais viável para o desfecho consensual, se conciliação ou mediação (TARTUCE, 2017).

Fredie Didier destaca que, até a edição do CPC, o mais importante instrumento normativo sobre a mediação e conciliação era a Resolução n. 125/2010, do Conselho Nacional de Justiça. Esta Resolução, por exemplo: a) institui a política pública de tratamento adequado de interesses (art. $1^{\circ}$ ); b) define o papel do Conselho Nacional de Justiça como organizador desta política pública no âmbito do Poder Judiciário (art.4º); c) impõe a criação, pelos tribunais, dos centros de solução de conflitos e cidadania (art. $7^{\circ}$ ); d) regulamenta a atuação do mediador e do conciliador (art.12), inclusive criando seu Código de Ética (anexo da Resolução); e) imputa aos tribunais a obrigação de criar, manter de dar publicidade ao banco de estatísticas de seus centros de solução de conflitos e cidadania (art. 13); f) define o currículo mínimo para o curso de capacitação dos mediadores e conciliadores (DIDIER JR., 2016, p. 272). 


\section{Vertentes do Direito}

ISSN n 2359-0106

Vol. 4, n. 2, 2017.

Pode-se consignar que as aludidas disposições buscam alcançar um processo rápido e eficiente, que possa viabilizar o acesso à justiça.

Entre os doutrinadores permeia a ideia de que a intenção é criar uma cultura do acordo, por isso mesmo é inserido já no início do processo uma audiência de conciliação e mediação de realização quase obrigatória - segundo determina o artigo 334, caput, do CPC, aquela só não se realizará se houver negativa expressa de ambas as partes - onde se objetiva solucionar o litígio através de acordo.

Assim, o que ocorreu no Brasil, com a emergência da novel codificação processual, foi um claro estímulo à solução de conflitos por autocomposição.

Lista-se que, para Fredie Didier (2016, passim) a solução negocial não é apenas uma forma eficaz e econômica de solução das controvérsias, mas também um instrumento que assegura a participação popular no exercício do poder, permitindo que as partes interessadas possam forjar a decisão que irá regular suas relações.

Diversas leis foram criadas na intenção de estimular a autocomposição, a saber: a) NCPC destina um capítulo inteiro para regular a mediação e conciliação (arts. 165175); b) a tentativa de autocomposição é posta como ato anterior ao oferecimento da defesa pelo réu (arts. 334 e 695); c) permite acordos processuais atípicos (art. 190), bem como a Lei 13.140/15, que regula de forma exaustiva a mediação. Hoje pode-se falar, nas lições de Fredie Didier, na existência de um princípio do estímulo da solução por autocomposição - para os casos em que ela é recomendável, por óbvio.

Referindo-se à mesma temática, Fernanda Tartuce (2017, passim) destaca que há uma priorização de chances para entabular acordos que vem se intensificando na seara judicial, tendência essa confirmada pela novel codificação. Sob as perspectivas numéricas, as ocorrências são as seguintes: no Novo CPC a mediação é mencionada em 39 dispositivos, a conciliação aparece em 37, a autocomposição é referida em 20 e a solução consensual consta em 7, o que totaliza 103 previsões. Soma-se a isso a Lei de Mediação (Lei 13.140/2015) e a Resolução 125/2010 do Conselho Nacional de Justiça. 
Por derradeiro, faz-se imperioso apresentar as ressalvas feitas por alguns processualistas no que tange à solução amigável dos conflitos. Segundo Nunes e Teixeira, por exemplo, não se pode festejar suas virtudes sem ressalvar suas ambiguidades e riscos.

Direcionam, assim, críticas latentes às soluções alternativas de litígio: de acordo com os autores, o movimento de solução alternativa de conflitos exige uma presunção de igualdade relativa entre as partes litigantes, trata o acordo como antecipação do resultado da decisão em juízo e pressupõe que seus termos são meramente um produto da vontade das partes. Mas, infelizmente, não é essa a realidade. O acordo é também um produto dos recursos que dispõe cada parte para financiar o processo judicial, sendo que tais recurso são, por vezes, distribuídos de maneira desigual.

\subsection{Acesso à Justiça no Estado Democrático: campo de implementação do Novo Código de Processo Civil}

A nova acepção de acesso à justiça pode ser concebida como a garantia de uma estrutura que permita o acesso à argumentação, à imparcialidade, à fundamentação, à certeza de que as decisões tomadas em favor ou prejuízo do jurisdicionado só se legitimarão se forem tomadas discursivamente (NUNES; TEIXEIRA, 2013, p. 67).

Pode-se inferir, então, o reforço do princípio do contraditório, que não pode mais ser visto como garantia do diálogo oferecido às partes, mas sim como poder que as partes possuem de influir na decisão. Soma-se a isso a exigência de que os fundamentos da decisão tenham sido fruto de algo debatido do âmbito do processo, de modo que qualquer decisão surpresa seja considerada nula.

Nunes e Teixeira, na linha de Habermas, acentuam que a tensão existente entre os interesses privados de cada cidadão e os interesses coletivo de bem comum só seria resolvida satisfatoriamente por um procedimento discursivo de formação da vontade e da opinião, ou seja, estes interesses contrapostos podem ser compatibilizados discursivamente, pela força dos melhores argumentos (2013, p. 56). 
Faz-se imperioso destacar que essa nova concepção de acesso à justiça não se satisfaz com a visão instrumentalizada da Jurisdição, seja como meio para satisfação de interesses privados (como no Estado Liberal), seja como instrumento para efetivação de valores sociais (como no Estado Social), ou mesmo com a figura do juiz como protagonista do processo, responsável por "compensar os défices de igualdade material", deixando as partes relegadas a segundo plano.

O que se vislumbra, portando, é a superação de brocardos como narra me factum dabo tibi jus ou iura novit curia em benefício de um debate mais aprimorado, capaz de viabilizar um melhoramento qualitativo do julgamento e suplantar a busca pela mera eficiência quantitativa e de produtividade. Busca-se a efetiva satisfação do sentimento de justiça do jurisdicionado, que jamais poderá ser correspondido com uma decisão proferida de forma mecânica.

Assim, consigna-se que há, no âmbito da novel codificação processual, uma ambiência propícia para a implementação de um acesso à justiça efetivamente democrático. Inúmeros são os regramentos capazes de assegurar tal afirmação, a saber: contraditório e a vedação da decisão surpresa, princípio da cooperação processual, o dever de fundamentação da decisão, de esclarecimento e o dever de prevenção.

O princípio do contraditório encontra-se assegurado no inciso LV, do art. 5 da Constituição Federal, segundo o qual "aos litigantes, em processo judicial ou administrativo, e aos acusados em geral são assegurados o contraditório e a ampla defesa, com os meios e recursos a ela inerentes".

Assevera Fredie Didier (2016) que o contraditório é um reflexo da estruturação democrática do processo. Democracia é participação, e a participação no processo opera-se pela efetivação da garantia do contraditório (DIDIER JR., 2016, p. 81).

O princípio do contraditório pode ser concebido sob duas perspectivas, quais sejam, a garantia da participação e a possibilidade de influência na decisão. A garantia da participação corresponde ao aspecto formal do contraditório, é o direito de participar 
do processo, de ser ouvido, de ser comunicado etc. Dessa forma, o órgão jurisdicional estaria efetivando o contraditório apenas oportunizando à parte o direito de se manifestar.

Há também o aspecto substancial do contraditório, correspondente ao "poder de influência". A oportunidade dada à parte de se manifestar não é suficiente para efetivação do contraditório. Exige-se que, para além de ser ouvida, seja a ela conferida condições de influir na decisão do órgão jurisdicional.

Assim, essa dimensão substancial do contraditório é responsável por prevenir o jurisdicionado da prolação de uma decisão surpresa, fundada em fatos não discutidos pelos sujeitos parciais.

A respeito do assunto, Leonardo Carneiro da Cunha lembra que:

O Estado democrático não se compraz com a ideia de atos repentinos, inesperados, de qualquer dos seus órgãos, mormente daqueles destinados à aplicação do Direito. A efetiva participação dos sujeitos parciais é medida que consagra 0 princípio democrático, cujos fundamentos são vetores hermenêuticos para aplicação das normas jurídicas (2012, p. 61).

Alguns dispositivos do CPC podem exemplificar essa nova visão do contraditório, a saber: a) artigo 772, II, que determina que o juiz, em qualquer momento da fase executiva, advirta ao executado que seu procedimento constitui ato atentatório contra a dignidade da justiça. Ou seja, antes de efetivar a punição, deve possibilitar que a parte se explique; b) artigo $77, \S 2^{\circ}$, que exige que 0 juiz, antes de expedir 0 mandado para o cumprimento de diligência, deve lembrar os sujeitos que são alvo de que seu comportamento poderá ensejar aplicação da multa mencionada. Fredie Didier (2016) sublinha que sem essa comunicação, a multa porventura aplicada é inválida, dado o flagrante desrespeito ao contraditório.

Conclui-se que o "contraditório se perfaz com a informação e o oferecimento de oportunidade para influenciar no conteúdo da decisão" (DIDIER, 2016, p. 83).

Dado os apontamentos, cumpre destacar algumas considerações a respeito das questões de fato e de direito a serem analisadas pelo juiz. 
Assim, estabelece o artigo 493 do CPC que o juiz, no momento de proferir a decisão, poderá levar em consideração, seja de ofício ou a requerimento das partes, fatos supervenientes modificativos, constitutivos ou extintivos do direito, capazes de influir na decisão. Lembre-se, o juiz poderá levar em consideração um fato de ofício, mas deverá oportunizar a possibilidade das partes se manifestarem a respeito, em observância ao contraditório. A regra geral está prevista no artigo 10, segundo o qual "o juiz não pode decidir, em grau algum de jurisdição, com base em fundamento a respeito do qual não se tenha dado às partes oportunidade de se manifestar, ainda que se trate de matéria sobre a qual deva decidir de ofício".

No que tange às questões de direito, "não pode o órgão jurisdicional decidir com base em um argumento, uma questão jurídica ou uma questão de fato não postos pelas partes no processo" (DIDIER, 2016, p. 83). O artigo $9^{\circ}$ do CPC consigna que "não se proferirá decisão contra uma das partes sem que ela seja previamente ouvida".

Como corolário do devido processo legal, da boa-fé processual e do contraditório, surge um outro princípio, o da cooperação.

O artigo 60 do CPC consagrou de forma expressa o art. $6^{\circ}$ "Todos os sujeitos do processo devem cooperar entre si para que se obtenha, em tempo razoável, decisão de mérito justa e efetiva".

Conforme ensina Fredie Didier (2016, p. 128), esse modelo se caracteriza pelo redimensionamento do princípio do contraditório, com a inclusão do órgão jurisdicional entre os sujeitos que dialogam no processo, deixando de ser espectador ser espectador imparcial do duelo assumido pelas partes. O contraditório, agora, passa a ser considerado um meio de aprimoramento do julgamento. Uma forma das partes influírem na decisão, e não apenas uma formalidade a ser observada para que essa decisão seja válida.

Há uma superação do modelo dispositivo do processo, onde as partes determinavam sua condução, bem como do modelo inquisitorial, onde a condução seria responsabilidade do órgão jurisdicional, para valorizar a condução cooperativa, feita através de diálogo e equilíbrio, sem protagonismos. Assevera Didier que esse é um 
"modelo de direito processual civil adequado à cláusula do devido processo legal ao regime democrático" (2016, p.128).

O aludido princípio possui eficácia imediata e sua aplicação não depende de regras expressas. Dele decorrem alguns deveres, indispensáveis para o modelo cooperativo, discriminados a seguir. Em relação às partes: a) dever de esclarecimento: demandantes devem redigir seus pedidos de forma clara e coerente, sob pena de inépcia; b) dever de lealdade: as partes não podem litigar de má fé (arts. 79-81 do (PC); c) dever de proteção: a parte não pode causar dano à parte adversária (art. 77, VI, CPC, art. 520, CPC e art. 776, CPC) (DIDIER JR., 2016, p.129).

Em relação ao órgão jurisdicional: a) Dever de esclarecimento: consiste no dever de o tribunal se esclarecer junto das partes em relação às dúvidas que tenha sobre suas alegações, pedidos ou posições em juízo, de modo a evitar decisões apressadas ou precipitadas. Sublinha-se que o dever de esclarecimento não fica limitado ao dever do Órgão Jurisdicional esclarecer-se junto das partes, mas também o dever de esclarecer seus próprios pronunciamentos para as partes (DIDIER JR., 2016, p. 129).

Lembre-se que esse dever de esclarecimento encontra concretização no artigo 489, $\S \S 1^{\circ}$ e $2^{\circ}$ do CPC, que consagra o dever de fundamentação das decisões pelo juiz, bem como no art. 357, § 3o do CPC, segundo o qual "se a causa apresentar complexidade em matéria de fato ou de direito, deverá o juiz designar audiência para que o saneamento seja feito em cooperação com as partes, oportunidade em que o juiz, se for o caso, convidará as partes a integrar ou esclarecer suas alegações".

O dever de prevenção: deverá ser observado sempre que houver, no processo, um erro passivo de ser sanado. Esse dever de prevenção, que determina que as deficiências das postulações das partes sejam apontadas para que possam ser supridas, foi consubstanciado no artigo 321 do Código de Processo Civil, para quem "o juiz, ao verificar que a petição inicial não preenche os requisitos dos arts. 319 e 320 ou que apresenta defeitos e irregularidades capazes de dificultar o julgamento de mérito, determinará que o autor, no prazo de 15 (quinze) dias, a emende ou a complete, indicando com precisão o que deve ser corrigido ou completado". 
ISSN nº 2359-0106 Vol. 4, n. 2, 2017.

\section{CONCLUSÃO}

O Novo Código de Processo Civil, ao ratificar garantias constitucionais entre as normas processuais fundamentais, procurou enfatizar que o jurisdicionado deve ter assegurado, entre outros, a solução efetiva e eficiente do seu litígio em tempo razoável. Não se contentou com a regra de que tais previsões independem de intermediação legislativa para alcançarem eficácia e tratou de positivá-las como forma de melhor alcançar sua satisfação.

Foram consagradas outras disposições que buscam alcançar um processo rápido e eficiente, que possa viabilizar o acesso à justiça, tais como os meios alternativos de solução de conflitos, fortemente incentivados no novo sistema de justiça. Fez-se isso, claro, sem deixar de lado as ressalvas feitas por alguns processualistas no que tange à solução amigável dos conflitos, a exemplo do que pensam Dierle Nunes e Ludmila Teixeira.

Ademais, concluiu-se que a codificação processual emergente apresenta inúmeras normas capazes de garantir a efetivação de um acesso à justiça democrático, fundado na cooperação processual, no poder de influência das partes nas decisões e no dever de fundamentação. Restam suplantados os tradicionais modelos dispositivo e inquisitivo em benefício de um terceiro modelo, o cooperativo.

\section{REFERÊNCIAS}

ALMEIDA, Diogo Rezende de Assunção de. O novo Código de Processo Civil e a crise da Justiça brasileira. Disponível em: < http://genjuridico.com.br/2015/09/17/onovo-codigo-de-processo-civil-e-a-crise-da-justica-brasileira/->. Acesso em: 15 de maio 2017.

CUNHA, Leonardo Carneiro da. A atentabilidade dos fatos supervenientes no processo civil: uma análise comparativa entre o direito português e o brasileiro. Coimbra: Almedina, 2012, 
Vertentes do Direito

ISSN n 2359-0106

Vol. 4, n. 2, 2017.

DIDIER JR, Fredie. Curso de Direito Processual Civil: introdução ao direito processual civil, parte geral e processo de conhecimento. Fredie Didier Jr. -18. ed.

- Salvador: - ed. Jus Podivim, 2016.

NUNES, Dierle; TEIXEIRA, Ludmilla. Acesso à justiça democrático. Brasília: Gazeta Jurídica, 2013.

NUNES, Dierle. O recurso como possibilidade jurídica discursiva do contraditório e ampla defesa. Puc-Minas, 2003.

OTTONI, Maria Clara Góis Campos. Acesso à justiça sob a perspectiva do novo código de processo civil. Disponível em: http://www.conteudojuridico.com.br/artigo,oacesso-a-justica-sob-a-perspectiva-do-novo-codigo-de-processo-civil,55842.html. Acesso em: 20 de mai 2017.

REVISTA CONSULTOR JURÍDICO. Lenio Streck e Dierle Nunes analisam mudanças trazidas pelo novo CPC. Disponível em: http://www.conjur.com.br/2016mar-25/lenio-streck-dierle-nunes-analisam-mudancas-trazidas-cpc. Acesso em: $17 \mathrm{de}$ maio 2017.

RODAS, Sérgio. Homenagem a Luiz Fux: para Celso de Mello, novo CPC vai democratizar acesso à Justiça. Disponível em: http://www.conjur.com.br/2014-dez18/celso-mello-cpc-democratizar-acesso-justica. Acesso em: 16 de maio 2017. SOUZA, Jessé (Coord.). A ralé brasileira: quem é e como vive. Belo Horizonte: UFMG, 2009.

TUCCI, José Rogério Cruz e. Garantia do processo sem dilações indevidas: responsabilidade do Estado pela demora na prestação jurisdicional. Rio de Janeiro: Forense, 2003.

GARCIA, José Antonio Tomé. Protección procesal de los derechos humanos ante los tribunales ordinários. Madri: Montecorvo, 1987.

TARTUCE, Fernanda. Estímulo à autocomposição no Novo Código de Processo Civil. Disponível em: http://www.cartaforense.com.br/conteudo/artigos/estimulo-aautocomposicao-no-novo-codigo-de-processo-civil/17017. Acesso em: 19 de maio 2017. 